Revista Mídia e Cotidiano

Artigo Seção Livre

Número 8. Março 2016

Submetido em: 19/01/2016

Aprovado em: 15/03/2016

\title{
O CORPO NA ERA DA SUA REPRODUTIBILIIDADE TÉCNICA
}

\section{THE BODY IN THE AGE OF MECHANICAL REPRODUCTION}

\author{
Marta CORDEIRO ${ }^{1}$
}

Resumo: $\mathrm{O}$ artigo questiona a possibilidade de serem copiadas aparências humanas a partir do exemplo do concurso televisivo I Want a Famous Face, no qual os concorrentes alteram o seu corpo de acordo com o modelo de uma celebridade. Considera a aproximação entre a posição dos concorrentes e a figura de Narciso, tomada como modelo do amor a si e utiliza a relação entre o corpo humano e as obras de arte para problematizar a ideia de cópia e reprodução no caso humano.

Palavras-chave: Corpo; Mídia; Cirurgia Estética.

Abstract: This paper explores the possibility people have to copy other people attending plastic surgery, by reviewing the television show I Want a Famous Face. Here, the competitors change their appearances having a celebrity as model. The paper considers the parallel between Narcissus - the figure who loves himself - and the competitors and uses the case of artworks to think about what is a copy, when the matter is the human body.

Keywords: Body; Media; Plastic Surgery.

\footnotetext{
${ }^{1}$ Marta Cordeiro doutorou-se em Belas-Artes - especialização em Teoria da Imagem, na Faculdade de Belas Artes da Universidade de Lisboa. É Professora Adjunta na Escola Superior de Teatro e Cinema do IPL e investigadora integrada do Centro de Investigação e Estudos em Belas Artes (CIEBA). E-mail: muitointeressante@gmail.com.
} 


\section{míDiA

Uma Face Famosa

No programa televisivo I Want a Famous Face, transmitido pela MTV entre 2004 e 2005, os concorrentes seleccionam uma celebridade como modelo e, em função dessa escolha, vêem a sua aparência transformada através da cirurgia estética. Em cada um dos episódios os espectadores têm acesso ao "antes" e ao "depois" da cirurgia, bem como à avaliação que os concorrentes, por norma jovens, fazem do processo.

Dois irmãos gémeos, Matt e Mike, de vinte anos, do Arizona, elegeram Brad Pitt como modelo pois, de acordo com os próprios, a aparência do actor (a perfeição da estrutura maxilar, do queixo, das maçãs do rosto e da estrutura óssea) seria a causa do seu sucesso, pessoal e profissional. Matt e Mike submeteram-se a cirurgias plásticas ao nariz, receberam implantes na face, trataram a pele através da colocação de uma máscara plástica e Mike recebeu, também, implantes no queixo.

Antes da cirurgia os jovens mostravam-se descontentes, tristes e pouco confiantes; findo o processo e aquando da sua avaliação, utilizaram expressões como "Sinto-me criado por Deus.", "Sinto que atingi o sucesso." ou "Estou feliz...pela primeira vez." ${ }^{2}$. Um e outro mostraram-se muito satisfeitos com os resultados e a avaliação denota a adesão à tese que relaciona aparência e personalidade pois, nas palavras dos irmãos, "A cirurgia alterou-me a vida, deu-me um novo fôlego na vida e permitiu-me ver a minha vida presente e futura à luz de uma nova perspectiva." 3 . A alteração da aparência promoveu o aumento dos sentimentos de confiança e a modificação da apresentação em público, o que se verificou na alteração da postura e forma de comunicar; reciprocamente, a relação com outros indivíduos tornou-se mais fácil, passando Matt e Mike a ser aceites e ser reconhecidos como "celebridades".

Uma das questões possíveis de isolar prende-se com a hipótese real de um cidadão anónimo se transformar em celebridade enquanto, em simultâneo, a integração

\footnotetext{
2“I feel like God created.” "I feel I achieved that success!”; “I am... happy for once.”. Matt e Mike em entrevista à MTV.

${ }^{36}$ The surgery has been life altering, it has given me a new lease on life, and has allowed me to view everything that consist of my life in the present and what I see as future, in a new light."

Op cit.
} 


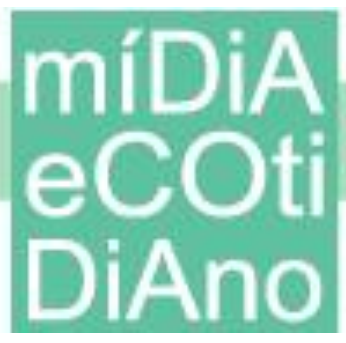

numa determinada elite deixa de estar subordinada à omissão dos procedimentos que a ela conduzem para serem esses procedimentos os responsáveis pelo reconhecimento público. Ou seja, Matt e Mike passaram a ser conhecidos por se terem transformado em Brad Pitt e não por serem o Brad Pitt; o importante é a exposição pública de um processo - o da cirurgia - cujo sucesso dependia, até à contemporaneidade, de ser mantido em segredo ${ }^{4}$.

A associação do consumo à liberdade e à auto-expressão e o seu enquadramento como mecanismo de construção das identidades (ROBINS, 1996) substitui o indivíduo vítima do mercado pelo consumidor livre que, em seu favor e por sua vontade, modela o seu corpo e é igualmente a passagem de vítima a consumidor que altera o estatuto simbólico de práticas como a da cirurgia estética. Se o início da cirurgia pretende fazer crer que os corpos por ela alterados são "naturais" (ou seja, pretende "fazer passar"), esse objectivo apenas pode ser cumprido se o processo for mantido em segredo. $\mathrm{O}$ entendimento contemporâneo da cirurgia prescinde desse apagamento e, embora existam (certamente) inúmeros casos de indivíduos que omitem a submissão à cirurgia e tentam fazer acreditar na "naturalidade" do corpo reformado, são igualmente múltiplos aqueles que a assumem, tanto ao nível das celebridades como nos exemplos dispersos por este e vários outros programas televisivos que relatam os processos de transformação de cidadãos comuns. Aquilo que era a anulação de uma marca - o nariz sifilítico ou a raça, por exemplo - pode agora ser a ostentação de um estilo de vida de sucesso, no qual o indivíduo dispõe dos meios necessários para aceder a um determinado produto e status correspondente ou, como em I Want a Famous Face, a cirurgia é a prova da determinação dos indivíduos em mudar (para melhor).

\footnotetext{
${ }^{4} \mathrm{Na}$ obra Making the Body Beautiful, Sander Gilman (1999) traça o percurso da cirurgia estética que, nos moldes como hoje é concebida, se inicia no século XIX e defende que o seu objectivo é o de "fazer passar", permitindo ao indivíduo apagar as características visíveis e distintivas de uma determinada filiação (raça, doença, género, classe) e permitindo-lhe a integração social. O sucesso do processo depende da sua omissão e, como exemplo pioneiro, Gilman refere a reconstrução dos narizes danificados pela sífilis.
} 


\section{míDiA \\ ecO DiAno}

\section{O Caminho da Cirurgia}

O conto The BirthMark (1843), de Nathaniel Hawthorne, narra a história de Georgiana, uma mulher bela que nasceu com uma marca na face. Apesar da maioria dos homens se sentirem encantados por Georgiana e considerarem a marca atractiva, o marido, um cientista de nome Aylmer, sente um incómodo crescente face ao sinal. Este mal-estar (que se transforma em ódio) começa a ser partilhado por Georgiana e o casal acorda submeter a mulher a uma experiência científica que remova a marca. Os momentos que antecedem a operação deixam Aylmer deslumbrado pois, nas suas palavras, "Nem mesmo Pigmalião, quando a sua mulher estátua adquiriu vida, sentiu um êxtase maior do que o meu será." (HAWTHORNE, 2006, p.70); no entanto, a marca contém a ligação entre o corpo e a alma de Georgiana e, no momento seguinte ao da remoção, Georgiana morre - o êxtase de Aylmer não dura mais que um instante.

A narrativa harmoniza-se com um contexto histórico que valoriza o conhecimento racional e confia na infalibilidade da relação entre ciência e técnica, capaz de alterar o mundo e os indivíduos. Simultaneamente, apresenta, como acontece na narrativa de Pigmalião e Galateia (que Aylmer utiliza como termo de comparação), a relação entre o criador masculino e a obra, ou o objecto feminino e que, de forma mais universal, diz respeito ao domínio do indivíduo sobre a matéria e, também, ao domínio da cultura sobre a Natureza. O ponto é que, ao contrário de Galateia que acede à vida, se emancipa do criador e o domina através do amor, Georgiana morre porque a remoção do sinal equivale à remoção da alma; ou seja, existe um local geograficamente determinado, situado no corpo, que encerra a ligação entre a alma, o corpo e a carne.

Determinar o sítio onde alma e corpo se cruzam é uma necessidade que existe desde a separação das duas entidades e Platão não deixou de determinar em que partes do corpo se albergavam as diversas almas - a alma imortal e racional na cabeça, a mortal e irascível no tórax e a mortal e concupiscível entre o diafragma e o umbigo. No entanto, a distinção entre alma e corpo no catolicismo, implica a noção da ressurreição do corpo, ou seja, a impossibilidade de separação entre alma e corpo e a consideração do corpo enquanto organismo, uma composição solidária que existe como conjunto e não pode, por isso, ser violada. É isto que nos diz o corpo de Cristo, uma unidade 


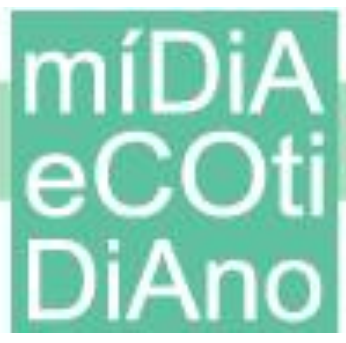

composta por todos os fiéis unidos pelo Espírito Santo. O corpo dos católicos pertence e encontra-se no corpo de Cristo e não existe forma de separar alma e corpo; é esta a premissa que é supostamente alterada quando a ciência decide abrir o corpo à análise, nomeadamente através da dissecção. A referência constante a Andreas Vesalius e ao seu tratado De Corporis Humani Fabrica (1543) justifica-se por ser um dos exemplos pioneiros ${ }^{5}$ em que a função de conjunto do corpo humano é anulada e se favorece a sua análise parcelar enquanto, em simultâneo, se deprecia o corpo de cada indivíduo naquilo que tem de particular e se valoriza uma ideia abstracta de corpo, o modelo. A dissecção permite abrir o organismo humano e expor órgãos, tecidos e nervos e é a necessidade de análise objectiva que leva Vesalius e preferir, como objectos, cadáveres que sejam "normais" no sexo e idade e o mais próximos possível do cânone de Policleto (ORTEGA, 2008, p.114), por forma a que o corpo dissecado seja um exemplo ou paradigma e se encontre, por isso, entre a média e o ideal. Esta preferência pelo exemplar harmoniza-se com a separação entre um sujeito que observa, do exterior, um corpo-cadáver que é objecto e não sujeito e deve, por isso, ser credível como motivo de análise.

A história da prática da dissecção é paralela à dos teatros anatómicos e à encenação de um espectáculo público que, apesar de pretender a objectividade analítica, não deixa de apresentar um conteúdo moralizante quando recorda a condição mortal dos humanos: no teatro anatómico de Leiden (c.1610) a exposição de esqueletos é acompanhada de legendas como "Conhece-te a ti mesmo." e "Nascemos para morrer."6, que dão conta da necessidade de considerar o "interior" para lá da falibilidade da carne.

Ao ponderar a ligação entre alma e corpo, Descartes (2000, p.91) resolveu com a glândula pineal. Nesta parte particular do cérebro encontrar-se-ia a ligação entre uma alma descarnada e a matéria do corpo e é esta relação entre alma e corpo que permite considerar a versão de Descartes reducionista ou localizacionista ${ }^{7}$. A distinção da res

\footnotetext{
${ }^{5} \mathrm{O}$ médico e anatomista Mondino De'Luzzi escreveu o seu tratado de anatomia Anathomia Mundini em 1316, baseado na dissecção de cadáveres humanos (ECO, 2007, p.249).

6"Nosce te Ipsum" e "Nascentes Morimus".

${ }^{7}$ Francisco Ortega (2008, p.66) cita Eva Thompson a propósito da relação entre alma e corpo se estabelecer no cérebro e ser reducionista ou localizacionista. Seguindo a autora, afirma que a visão de Descartes relativamente ao corpo é a de um proto-embodiment e que, contrariamente à consideração do
} 


\section{míDiA

cogitas (a substância pensante) da res extensa (a extensão física) encontra-se contida na conhecida premissa "penso, logo existo" que implica que, embora possa duvidar de tudo o que existe, o sujeito não pode duvidar do facto de ter dúvidas, ou seja, não pode duvidar do seu raciocínio; para tanto, é necessária uma substância pensante que raciocine e esta não necessita da extensão ou de qualquer qualidade que dependa e possa ser atribuída ao corpo, independência que garante a individualidade do cogito (DESCARTES, 1998, p.55). Neste contexto, Descartes considera que o funcionamento do corpo é independente da acção de quaisquer “(...) forças ocultas (...)" (COTTINGHAM, 1995, p.140) e que decorre da configuração e relação dos órgãos, que pode ser vista pelo olho humano. Quando estuda o coração e a circulação do sangue e descreve o sistema de artérias e válvulas, observa que a expansão e circulação do fluxo sanguíneo depende do seu aquecimento e da configuração do coração e é neste momento que compara o sistema ao funcionamento de um relógio, cujo movimento depende, de forma equivalente, das formas das peças, contrapesos e engrenagens (DESCARTES, 2000, p.41-43).

Se Descartes atribui à glândula pineal a função de ligar corpo e alma ${ }^{8}$, existem outros estudiosos cuja observação conclui que não existe qualquer ponto específico em que se dê a união, podendo a alma encontrar-se em qualquer parte: o médico Thomas Willis (1621-1675) estuda o sistema neurológico e afirma não existir qualquer ponto observável onde a alma se situe e Claude Bernard (1813-1878) nota que nunca, nos vários cadáveres que dissecou, encontrou a alma (MIRANDA, 2008, p.86). O estudo do interior do corpo confirma a sua separação da alma (ou da consciência) e a comparação entre o funcionamento do corpo e o de um relógio encaixa numa concepção mecanicista do corpo que privilegia a relação entre as partes em detrimento do todo, sendo agora possível reparar ou substituir órgãos de forma a manter o bom funcionamento da estrutura, lógica que é cara à medicina ocidental.

corpo como mero objecto e sua referência como uma terceira pessoa, Descartes fala do corpo na primeira pessoa, na qualidade de um ser corporizado.

${ }^{8}$ A ideia de "homem-máquina" encontra-se igualmente relacionada com Julien de La Mettrie que, em 1747, publica L'Homme Machine. Se Descrates distingue corpo e alma, La Mettrie associa a alma (ou o espírito) ao cérebro e propõe a associação entre alma e corpo. A alma pode apenas ser estudada através do corpo, pelo que se depreende uma origem mecânica para as manifestações da alma (MEDEIROS, 2010, p.63-68). 


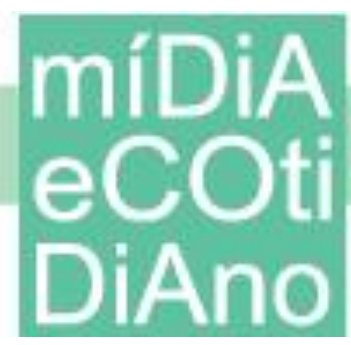

Daniel Dennett (2001) considera a afirmação de Descartes que faz equivaler os animais a robots e diz que a mente é um atributo humano. Para Descartes, o indivíduo seria a sua mente e a glândula pineal o canal onde a informação física é traduzida em informação mental; Dennett avança a hipótese da substituição de todas as substâncias do corpo por um sistema químico diferente e conclui que os materiais de que corpo e mente são feitos importam e que as mentes e os corpos dependem daquilo que os compõe porque são estas matérias que são compatíveis com as funções que se pretende que desempenhem, sendo esse um dado histórico-biológico. Dennett questiona aqueles que afirmam que “(...) eu não sou o meu corpo, mas aquele que possui... o meu corpo."(DENNETT, 2001, p.93) e considera que o corpo contém muito do “eu", os valores, as capacidades, as memórias e as disposições que fazem um indivíduo ser de determinada maneira e não de outra. Ao mostrar-se avesso ao pensamento cartesiano e rejeitar a hipótese do cérebro controlar o corpo, diz antes que o cérebro (e a mente) é um órgão entre outros, que não chefia mas trabalha para servir os interesses do corpo, o corpo “(...) que o abriga e dá sentido às suas actividades.” (DENNETT, 2001, p.93). A proposta é de abandonar a distinção entre corpo e mente para aceitar que a sabedoria está disseminada por todo o corpo. Aqui, cita a passagem Dos que Desprezam o Corpo, de Nietzsche, quando a criança diz "Eu sou corpo e alma. (...) a "alma é uma palavra que designa uma parte do corpo. (...) Habita o teu corpo, é o teu corpo. Há mais razão no teu corpo do que na própria essência da tua sabedoria." (NIETZSCHE, 1883, apud DENNETT, 2001, p.94).

Se, na prática, o corpo passou a ser tratado a partir da lógica da máquina, reparandose e substituindo-se partes ou órgãos, persiste também uma visão do corpo como qualquer coisa de especial, como símbolo de uma humanidade inviolável que garante a espécie. Da mesma forma que os humanos acreditaram ser o centro do Universo, tendo o sol a girar em seu torno e desconfiaram da hipótese levantada por Darwin quanto às suas origens, persiste um mal-estar relativamente à ideia de que o corpo possa ser apenas matéria. Assim, o "corpo-organismo", especial e filho de Deus, convive com o paradigma do "corpo-máquina" - o corpo é a última obra de arte a que se pode atribuir a emanação de uma "aura", por ser criado por Deus à sua imagem e semelhança e por isso 
diverso de qualquer outro ser vivo; mas é um corpo que convive, agora, com a recriação, transformação e reprodução tecnológica, alterações que o privam, segundo Walter Benjamin", do "aqui e agora" ou da função ritual que garante a autenticidade e é constituinte da "aura". A singularidade do corpo depende deste ser, por um lado, o corpo de cada um, aquele que contém informação privada e onde o "eu" se projecta e constrói e, por outro, deste corpo ser humano e, por isso, diverso do dos animais, capaz de albergar a alma ou, como afirma Descartes, ser uma máquina especial, mais complexa porque criada por Deus.

Entender o corpo como sendo especial permite associar-lhe uma aura, conceito que Walter Benjamin associa à obra de arte e define através de expressões como “(...) o aqui e agora do original [que] constitui o conceito da sua autenticidade(...)", “(...) manifestação única de uma lonjura (...)”, “(...) carácter único (...)”, “(...) função ritual (...)", “(...) valor de culto (...)" ou “(...) melancolia e beleza (...)" (1992, p. 77-87). A reprodução mecânica colocaria em causa a aura, em grande parte devido à ligação entre a aura e a autenticidade e à associação entre a autenticidade e o toque ${ }^{10}$ do artista na obra sendo que, aqui, a aura depende da singularidade impressa através do corpo. Aleida e Jan Assmann (In MARRINAN ; GUMBRECHT, 2003, p.153) vêem na "lonjura", na experiência da distância e na "nostalgia" a tentativa de capturar algo que se encontra já perdido, sendo esse elemento ausente o que define a verdade e a aura do objecto de arte. Epistemologicamente, aura vem do grego e do latim av́ $\alpha$, que significa "brisa

\footnotetext{
${ }^{9}$ Referência ao conceito de aura proposto por Walter Benjamin e relativo à questão da reprodução das obras de arte através de processos mecânicos (BENJAMIN; 1992).

“(...) Benjamin becomes de retrospective prophet of aura when he speaks of values that are irredeemably lost and gone, values that find their last shrine in his very words. It is a difficult to describe what Benjamin means by aura as it is easy to memorize his "concise" definition of it as "the experience of distance, however far that may be which brought it about". The problem with aura is that one is trying to describe something lost and absent rather than something extant to which one can refer indexically. In fact, Benjamin is not really describing it at all, but rather constructing it in the moment of its supposed vanishing. Hence, the nostalgia of his concept that struggles to capture a loss, one rather loosely defined as the element of art "which is not reproducible". This vanishing element, supposedly the "truth" of a work of art, is what Benjamin calls its aura.

ZUMTHOR, Paul - Concerning Two "Encounters" with Walter Benjamin. The Reproducibility of Art. In MARRINAN, Michael ; GUMBRECHT, Hans Ulrich (ed.). Mapping Benjamin: The Work of Art in the Digital Age. p.153.
}

10"Whatever is considered to be authentic has been in touch with the body of an author (...)" (MARRINAN ; GUMBRECHT, 2003, p.127). 


\section{míDiA \\ ecc DiAno}

suave" e o termo estabeleceu-se na arte romana nas representações de Aurae, personificações de uma "doce brisa", o que leva os autores a afirmar que falar de aura implica recorrer a uma experiência do mistério - é esta brisa, um "sopro de verdade" que existe no corpo e que Benjamin reconhece existir quando diz que o actor de cinema se encontra privado de aura pois, ao transformar-se em imagem, deixa de ter no corpo o garante do "aqui e agora".

Didi-Huberman enfatiza o “(...) poder da distância (...)” (2011, p. 117) como o que caracteriza a aura, sendo o dom de estar próximo e distante em simultâneo e de mostrar a sua distância aquilo que garante a experiência da obra como um momento único. É a distância e a dificuldade no acesso que se encontra implícita, também, ao valor de culto (BENJAMIN; 1992, p.84-87) - por oposição ao valor de exposição e à reprodutibilidade - e é a inacessibilidade que faz Didi-Huberman projectar o valor de culto na experiência religiosa e no exemplo de Verónica ${ }^{11}$, a imagem que se furta permanentemente aos olhos do crente e onde o espectador deseja ver Cristo - ver para além da imagem, “(...) ver a aura, justamente." (DIDI-HUBERMAN, 2011, p.123). No caso do corpo, a aura encontra-se garantida desde que o corpo foi modelado pelo exemplo do corpo de Cristo, um corpo cuja situação é a de estar permanentemente além e exigir a crença e, por isso, concordar com todas as aproximações que definem a aura e a autenticidade: o único, o ritual, o culto, a "brisa de verdade".

\section{A Cópia}

Em What Not to Wear $^{12}$ e Extreme Makeover ${ }^{13}$ adivinha-se ou conhece-se um modelo que é, apesar de tudo, abstracto no sentido de ser uma ficção ou um protótipo do que se supõe ser a beleza humana; em Style Her Famous ${ }^{14}$ e I Want a Famous Face

\footnotetext{
${ }^{11}$ Referência à passagem bíblica em que, ao caminhar para o calvário, o rosto de Cristo é limpo com um pano e, nele, surge a sua face - a verdadeira imagem do Seu rosto.

${ }^{12}$ Programa televisivo transmitido desde 2003 que propõe a alteração de vestuário, cabelo e maquilhagem dos concorrentes. Auxiliados por dois consultores de moda, os concorrentes adquirem um novo guardaroupa, selecionado de acordo com os critérios dos consultores.

${ }^{13}$ Programa televisivo emitido desde 2002 em que os indivíduos alteram a sua aparência através de cirurgias plásticas, reconstituições dentárias, correcções oftalmológicas e dermatológicas, rigorosas dietas alimentares e treino em ginásios, alteração do cabelo e maquilhagem.

${ }^{14}$ Programa televisivo em que, guiados por um consultor de moda, os concorrentes escolhem uma celebridade como modelo e, a partir daí, alteram o vestuário, cabelo e maquilhagem em função desse modelo. Como conclusão, protagonizam uma sessão fotográfica com um fotógrafo de moda.
} 


\section{míDiA

existe alguém, uma celebridade, cujo papel excede a função de protótipo, a celebridade é o modelo que deve ser imitado. Ao caracterizar os vários graus de cópias, James Elkins (1993, p.116) refere que o termo "imitação" invoca a oposição italiana entre "imitação" (imitazione) e " imaginação" (fantasia) e refere os pontos de vista divergentes que ora consideram que a imitação apenas pode ser fiel ao original se for recriada através da fantasia, ora defendem a imitação estrita e a absoluta precisão no encontro entre original e imitação. Inicialmente, o termo foi usado pelo poeta Robert Lowell para descrever poemas que "imitavam" mas não transcreviam o original, o que supõe a alteração do original. A inclusão da fantasia encontra-se subjacente às mudanças a que os concorrentes de Style Her Famous e I Want a Famous Face se sujeitam, sendo a diferença fundamental entre os dois programas de televisão o grau de investimento que a alteração sugere: no primeiro caso existe uma encenação da aparência realizada de forma lúdica e efémera, sendo que a fixação da experiência é feita através do registo fotográfico; no segundo caso, a alteração implica permanência, tendo em conta que os procedimentos cirúrgicos, embora reversíveis, são irreversíveis até ao próximo acto médico. A encenação proposta em Style Her Famous não se encontra longe das transformações realizadas por um actor que utiliza o figurino e a caracterização para interpretar e encenar um personagem, o que supõe que quando o espectador decidir não "suspender a descrença" ${ }^{15}$ possa sempre ver o actor - no caso do concuro, o concorrente - para além da máscara. A relação entre superfície-essência ou imagem-verdade não se altera neste caso pois, para lá da encenação de $x$ encontra-se o concorrente, o "verdadeiro indivíduo". Esta separação colapsa no caso de I Want a Famous Face pois a encenação torna-se definitiva não sendo possível encontrar o verdadeiro corpo de Matt ou Mike para lá da aparência de Brad Pitt: ao olhar para Matt ou Mike vê-se sempre Brad Pitt. Walter Benjamin (1992, p.90-95) analisa a diferença entre teatro e cinema e observa que a relação física que une espectadores e actores no

\footnotetext{
15 Expressão do poeta e filósofo Samuel Taylor Coleridge, proposta em em 1817, que se refere a uma suspensão do julgamento a que os espectadores se permitem na análise de um objecto ficcional, de forma a ultrapassar limitações, incoerências e impossibilidades para alcançar uma “(...) fé poética (...)"(COLERIDGE, 1983, p.6).
} 


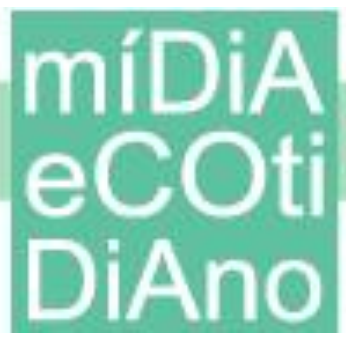

teatro mantém a ideia de aura quando, opostamente, a mediação da câmara no cinema a interdita e, como consequência da perda de aura, propõe o culto das estrelas, alicerçado numa personalidade regida pelo carácter mercantil. Quando Stanley Cavell estuda o papel dos actores de teatro e cinema conclui que, como por norma, os actores do teatro não são celebridades e não são conhecidos pela generalidade do público, a sua aparição nunca remete para si próprios mas sempre para a personagem interpretada; no cinema, exactamente porque os actores são celebridades, a sua performance excede o domínio da personagem interpretada e aponta sempre para o indivíduo, para o nome próprio. «No palco, o actor trabalha-se para um papel; no ecrã, o performer assume o papel para si mesmo» (CAVELL, 1979, p.27): a diferença existe, até, nas palavras que Cavell emprega, sendo que no teatro Cavell usa o termo "actor" e no cinema prefere "performer" pois, no primeiro caso, o autor afirma existirem dois seres, o personagem e o actor, o último constantemente assaltado pela personagem e sobrevivente a custo; no ecrã, por seu turno, o performer é sempre um sujeito, $o$ sujeito.

Ver Brad Pitt a interpretar Benjamin Button ${ }^{16}$ implica reconhecer e ter permanentemente presente Brad Pitt para lá da aparência de criança ou de idoso de Button; de forma análoga, ver Matt ou Mike implica reconhecê-los como casos de transformação e ver, para lá deles, Brad Pitt.

Elkins distingue tipos ou graus de cópias, uma delas a imitação, outra a cópia estrita (que envolve uma cópia fotográfica), a reprodução (que integra a distância formal e estética, como nas obras da artista Sherrie Levine), a variação (caso da caricatura, paródia ou pastiche) e a versão (um quase segundo original) e por muito que Matt e Mike possam pretender ser cópias estritas, serão sempre imitações, reproduções, variações ou versões, tendo em consideração as actuais limitações científicas e técnicas que impedem a semelhança exacta e que não podem ainda prescindir das qualidades do corpo que aceita a cirurgia. Elkins demonstra que a originalidade da criação artística conta com o diálogo entre original e cópia e o facto é que qualquer cópia valoriza o original e reforça o seu estatuto. Benjamin distingue cópia e falsificação: a cópia não coloca em causa a autenticidade, tendo em conta o facto da cópia se assumir como tal e

\footnotetext{
${ }^{16}$ Referência à interpretação de Brad Pitt em The Curious Case of Benjamin Button.
} 


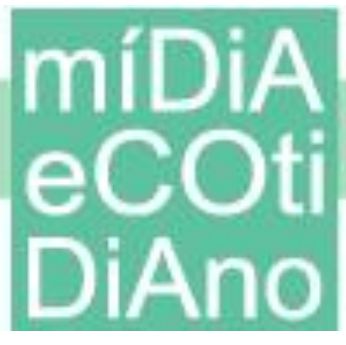

precisar do original para a sua existência e afirmação; a falsificação, por seu turno, é uma cópia que pretende ser o original.

Cópia e falsificação são categorias normalmente aplicadas a objectos e, no caso dos humanos, utiliza-se de forma mais óbvia as expressões impostura (imposture) e representação (impersonation), categorias que Hillel Schwartz (1998, p.72) distingue: a primeira será a assunção compulsiva de vidas inventadas - o que estaria de acordo com uma interpretação quase caricatural da necessidade contemporânea de construção da identidade -, a segunda a adopção premeditada de uma identidade pública. Matt e Mike não se limitam a viver uma ficção mas estão igualmente longe de usurpar a identidade de Brad Pitt, uma vez que o seu sucesso depende da existência de Brad Pitt. Matt e Mike são cópias de Brad Pitt mas estão igualmente longe de convocar as dúvidas com que se debate, por exemplo, a figura do clone porque estas cópias apenas mimam a aparência e não se encontra subjacente o paradoxo filosófico que questiona o facto de duas pessoas com o mesmo corpo serem ou não a mesma pessoa e que se resume na narrativa do barco de Teseu (CORREIA, 1996, p.184): Teseu, o herói grego, tinha um barco de nome Ariadna, construído por pranchas de madeira. A estadia prolongada no mar leva a que as pranchas sejam gradualmente substituídas até que, sem que Teseu se aperceba, a última prancha original é substituída. Com as pranchas removidas, um construtor naval constrói um outro barco, seguindo o mesmo modelo do de Ariadna. Teseu afirma que sempre navegou no mesmo barco e que o barco construído pelo armador é apenas semelhante a Ariadna; o construtor diz que o novo navio é idêntico ao primeiro, na matéria e na forma. O paradoxo é que ambos dizem a verdade o que, quando aplicado ao corpo e pensando num corpo em que todas as células fossem substituídas por outras, coloca uma questão semelhante: é ou não o mesmo corpo?

Ainda assim, é possível transcrever algumas das questões associadas à clonagem (ATLAN, 2001) e colocá-las a propósito de Matt e Mike, nomeadamente a identificação simbólica entre a unicidade do rosto e a identidade; a existência de um modelo e de uma cópia (o que implica o estabelecimento de critérios que definam quem deve ser copiado); a diluição da possibilidade de construção da identidade através da diferença 




entre o "eu" e o Outro e a anulação da diversidade a favor da eleição de modelos considerados belos, agora efectivada.

\section{Matt e Mike ou Narciso?}

No mito de Narciso ${ }^{17}$ o fundamental é o facto deste se ter apaixonado por uma imagem que, como o próprio veio posteriormente a verificar, era o seu reflexo. Mitchell (2005, p.58) utiliza a expressão deadly lure, possível de traduzir como "logro mortal" ou "engodo mortal", sendo que engodo remete imediatamente para um ardil ou uma forma astuciosa de seduzir ou fixar a atenção de alguém, ou «(...) enganar com promessas vãs.»(COSTA, 1999, p.619). A imagem assume, neste caso, o estatuto que a associa ao perigo do engano, à falácia, papel que lhe assenta desde a repulsa platónica da imagem e que Martin Jay (1986, p.177) resume como sendo o paradoxo da cultura visual: a imagem como possibilidade de contemplação de realidades virtuais e extraordinárias e a imagem como falsidade e, em paralelo, o indivíduo como sujeito da observação ou como objecto de vigilância. No mito, o facto de Narciso se ter deixado seduzir permite considerá-lo na qualidade de objecto vítima do engano - não fosse o facto de Narciso ter escolhido o engodo - e aproximar o papel de Narciso da posição dos espectadores contemporâneos vistos através das teses de Adorno (2003) ou da radicalização de Debord (2005) que ligam a indústria da cultura, encimada pela televisão, à alienação dos espectadores. Para tanto, a água de Narciso teria que se equiparar ao ecrã - se a água de Narciso é o local da imagem é, por definição, superfície e profundidade. Esta dupla valência caracteriza a água onde Narciso se mira, pois para lá da superfície da água e do reflexo existe um espaço onde Narciso projecta a existência de um outro e existe, de facto, um espaço em profundidade que, por ser vivo, integra o movimento (a impossibilidade enunciada por Heraclito de um homem se banhar duas vezes no mesmo rio). O ecrã é, igualmente, uma superfície que contém uma

\footnotetext{
${ }^{17}$ Narciso é um jovem muito belo, filho de uma ninfa, a quem o oráculo diz que apenas viverá se não se conhecer. Muitos são os pretendentes de Narciso, que a nenhum corresponde. Certo dia, Narciso passeia na floresta e, quando se aproxima de uma fonte para beber água, apaixona-se pela sua imagem refletida. A princípio, Narciso desconhece tratar-se do ser reflexo mas, mesmo quando o descobre, decide não abandonar essa imagem e, por isso, morre.
} 


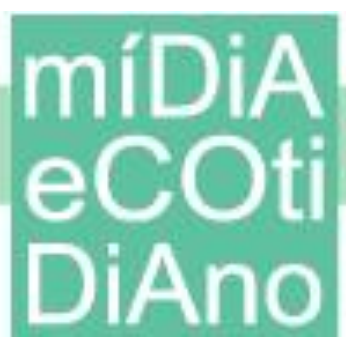

profundidade e, enquanto superfície, nega aquilo que a define por ser um interface fluido que conta com o movimento dos signos. Cavell (1979, p.24) vai mais longe e afirma que o ecrã não é um suporte, como a tela, porque não existe nada (como a tinta) a suportar, o que existe é a projecção de luz e, por isso, fala do ecrã como uma barreira que separa o indivíduo e o seu mundo desse outro mundo contido no «contentor que é o ecrã. Para lá do ecrã existe um mundo virtual, um “(...) oceano-imagem (...)” nas palavras de Alain Gauthier (1999) - como é líquida a modernidade contemporânea ${ }^{18}$-, um espaço que, por norma, se associa à janela de Alberti através do azul que caracteriza o ambiente Windows (janela) ${ }^{19}$ mas que pode, por intermédio do mesmo azul, associarse às águas de Narciso e ao sonho através do qual Bachelard as descreve: «(...) a água é também um tipo de destino, não mais apenas o vão destino de um sonho que não se acaba, mas um destino essencial que metamorfoseia incessantemente a substância do ser.» (1989). No virtual de que fala Gauthier, o indivíduo prescinde de um corpo físico e entra numa zona movediça caracterizada pela interacção sem esforço, sem inquietação ou incerteza.

É a essa passagem que se refere Paul Virilio (1991, p.64-65) quando utiliza o cinema para entender e caracterizar a arquitectura: no cinema, os instantes entre frames falam mais do que desaparece do que daquilo que aparece e este desaparecimento é o que se encontra subjacente ao ecrã como paradigma de visualização. A cidade deixa de ser um teatro para ser um cinema saturado de ecrãs, o que implica a perda do real a favor da relação empática com o ecrã - individualmente e em especial na relação que estabelece com a televisão, o autor sublinha a substituição do que se encontra perto, a comunidade de vizinhos ou amigos, pelo que se encontra longe, o personagem que habita o ecrã (VIRILIO, 2000, p.46-54).

Matt e Mike deixaram-se seduzir por uma imagem e extinguiram efectivamente a distância que separa indivíduo e imagem. Mas, se o colapso entre indivíduo e imagem

\footnotetext{
${ }^{18}$ Referência ao título da obra de Bauman (1997) que foca a passagem da "modernidade sólida" para um estado líquido, onde tudo é relativo e volátil e onde a realidade se caracteriza pela flexibilização das relações afectivas e sociais tendo como consequência, para o indivíduo, a sensação crescente de liberdade e de desamparo.

${ }^{19} \mathrm{~A}$ este propósito V.BOLTER, Jay David ; GROMALA, Diane. Windows and Mirrors. Interaction Design, Digital Art, and the Myth of Transparency. p.42.
} 


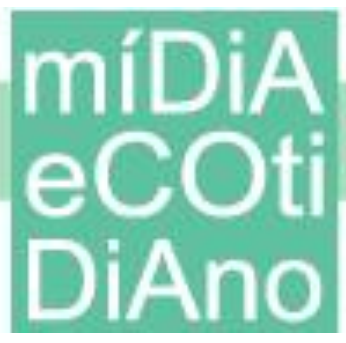

(sujeito e objecto) que se encontra subjacente ao mito de Narciso depende de indivíduo e imagem pertencerem à mesma entidade - Narciso - e da separação entre ambos sujeitar-se, primeiro, a um engano, esse engano só é mantido por vontade de Narciso e através do interface (a água). Em contrapartida, a imagem de Brad Pitt não pertence a Matt e Mike e não existe engano que justifique a escolha dos irmãos. Por outro lado, o interface é suplantado e o ecrã (tomando Brad Pitt como imagem cuja circulação privilegia o cinema e a televisão ou tomando o ecrã com o significado alargado de media) é destituído da função de fronteira: a imagem de Brad Pitt sai do ecrã e assume um corpo tridimensional. Se o líquido de Gauthier é o virtual, a ligação física entre Narciso e reflexo é metafórica, pois advém da correspondência entre os líquidos do olho e da água. Em I Want a Famous Face, a ligação entre Matt e Mike e a imagem constitui-se de facto através do corpo. A estranheza é a de a imagem não ser o reflexo e não pertencer, por isso, aos irmãos; Matt e Mike apropriam-se da imagem de alguém, ou de alguém que existe publicamente como imagem e, ao fazê-lo, tornam equívoca a relação que existia entre Narciso e o reflexo de Narciso e que se estruturava de acordo com a hierarquia das partes: o reflexo existe numa relação analógica que subentende a dependência entre imagem e referente. É esta a lógica da mimesis, que Phillipe Dubois descreve como “(...) analogon objectivo do real.” (1991, p.20) e que indica uma semelhança perfeita entre imagem e referente.

No entanto, a imagem de Brad Pitt não depende da existência de Matt e Mike e, ao prescindirem dos seus rostos a favor do de Brad Pitt, os jovens reforçam o estatuto da imagem pois são eles que existem à semelhança da imagem; o original é enaltecido através da sua reprodução ou, de forma mais enfática, o modelo existe através da sua confirmação no real. Esta posição está nos antípodas do costume, por exemplo, de Andy Warhol e Edie Sedgwick tornarem as suas aparências semelhantes e saírem juntos, como cópias um do outro: "Andy Warhol e Edie Sedgwick. Andy e Edie. Eles eram como um acto duplo. Sabes, ela pintou o cabelo de prateado por um tempo, e eles saíam como um casal.” (McNEIL ; McCAIN, 2006, p.11). Neste caso, Warhol e Sedgwick são os modelos um do outro, pelo que não existe um deles que se que se preste a ser copiado e seja identificável como modelo e a sua acção, que será sempre lida em função de um 


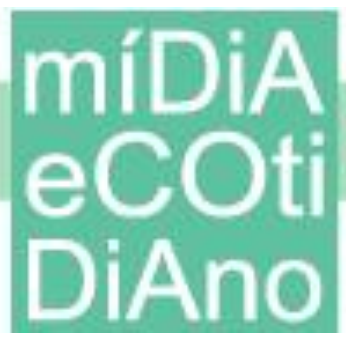

contexto (o da produção artística e o da cena norte-americana da década de setenta do século XX), coloca em causa o papel e definição de cópia enquanto, ao mesmo tempo, evidencia a originalidade do par através da acção pouco comum da transformação de dois indivíduos em cópias um do outro.

Em Are Persons Bodies, Bernard Williams concebe a existência de um corpo e de cópias feitas a partir desse corpo: como cópias, passariam a ter experiências diversas das do protótipo pelo que, quando vistas como cópias, seriam cópias “( ...) turvas ou reescritas (...)" (WILLIAMS, 1970, p.81) e quando observadas enquanto pessoas de direito próprio seriam personalidades individuais. Por exemplo, alguém se apaixona por uma cópia de Mary Smith; se o apaixonado gostar da cópia apesar desta ser Mary Smith, amá-la-á tanto mais quanto ela se afastar do protótipo e se constituir como pessoa de direito mas se, pelo contrário, o apaixonado amar a cópia como Mary Smith, a situação será equivalente ao interesse pela reprodução de uma obra de arte. No âmbito dos objectos, o sentido de obras como After Walker Evans (obra em que a artista fotografa as reproduções das fotografias de Walter Evans, a partir de um catálogo, em 1981) ou de Fountain, After Marcel Duchamp (escultura de 1991, produzida em bronze, que replica o urinol de Duchamp) de Sherrie Levine depende da existência das fotografias de Walker Evans e do urinol de Duchamp e a adesão à obra de Levine fazse, em simultâneo, por causa de Evans e Duchamp e apesar de Evans e Duchamp. A perplexidade que emerge no caso das pessoas é, então, a mesma que atinge os clones - é possível que o sentido de alguém dependa de um outro?, ou é possível gostar de alguém por causa ou apesar do modelo de um outro? O que equivalerá a questionar a individualidade, a liberdade e a responsabilidade como pilares da construção das identidades e como características irredutíveis do género humano.

\section{A Aura, a Alma}

Narciso deseja separar-se do seu corpo quando percebe que, aquele que ama, é ele mesmo; Matt e Mike desejam amar-se e, para tanto, usam a estratégia de se aproximarem da aparência de um outro. O objecto de amor que Narciso excluiu ao amar-se a si mesmo é fortalecido através da acção dos irmãos - olhar para Matt e Mike 


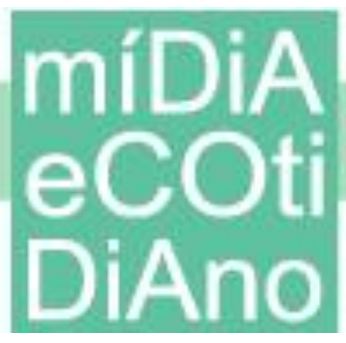

é olhar para a imagem de Brad Pitt ou, como na análise de Stanley Cavell, olhar para Matt e Mike como se fossem Brad Pitt a interpretar um papel (o de Matt e Mike) e ver, para além dele, o sujeito Brad Pitt. Matt e Mike remetem para Brad Pitt e, a acreditar nas palavras do actor Phil Boroff, parecido fisicamente com Woody Allen ${ }^{20}$, julgar os irmãos a partir da proximidade das suas performances às de Brad Pitt. Querer ser igual a Brad Pitt é querer, por intermédio do corpo, ser bem sucedido como o modelo e "passar" não como sendo Brad Pitt mas como tendo uma "boa personalidade", como Brad Pitt. Os irmãos perseguem o sucesso do modelo, ou um nível de sucesso semelhante (como celebridades).

No mito, a morte de Narciso é determinada pelo oráculo que, ao impedir Narciso de se conhecer, estabelece uma relação de causa-efeito entre ver e conhecer: ao olhar-se, Narciso estaria a desvendar-se quando, opostamente, ver a aparência reformulada de Matt ou Mike é diferente de ver e conhecer Matt e Mike mas é, igualmente, diferente de ver e conhecer Brad Pitt, por muito que possa ser evocada a presença da aura do actor. A relação (platónica) entre ver e conhecer, que equivale a convocar a relação entre aparência e verdade, é destruída quando deixa de ser possível recorrer ao expediente que assenta na legibilidade do rosto e recorda a possibilidade de encontrar, no rosto, nos olhos, a verdadeira alma.

Imaginar que todos podem ser iguais lembra o apelo e a angústia contida na afirmação de David, a personagem da película A.I. Artificial Intelligence, quando diz, “Sou especial! Sou único! Sou o David!” (SPIELBERG, 2001). David faz este desabafo quando descobre que é um robot igual a tantos outros num armazém onde, embalados, estão inúmeros robots iguais a si mesmo e é o facto de terem corpos iguais que denuncia a sua produção em massa, a sua reprodutibilidade técnica.

A luta pela unicidade está contida, ainda, em algumas narrativas ancestrais e ficções literárias onde, basicamente, o indivíduo e o duplo dividem a existência de um “eu” bom e outro mau. É assim em A Sombra (1847), de Hans Christian Andersen, onde

\footnotetext{
20"'You cannot escape a person toy look like. All the associations that a person has, good or bad, for a celebrity they have for you."

Phil Boroff, cit. por SCHWARTZ, Hillel. The Culture of the Copy. Striking Likenesses, Unreasonable Facsimiles. p.329.
} 


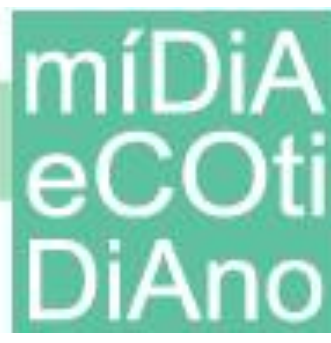

a sombra autonomizada (o duplo) é mesquinha e tirana e em William Wilson (1839) de Edgar Allan Poe, que termina com a morte de um dos Williams que, em consequência, condena o assassino à sua própria morte. A presença e o medo do duplo existe, igualmente, em tradições como a do evil twin ou do doppelgänger. O medo dos gémeos encontra-se em algumas lendas de tribos africanas, que conotam o seu nascimento com o regresso da alma dos mortos ou com a má sorte (é curioso observar que Matt e Mike são gémeos, pelo que a angústia de ter alguém igual a si parece não existir e, ao contrário, a existência prévia de um semelhante pode servir como factor que torna comum ver-se reflectido num outro). O medo existe, também, na crença de um "gémeo bom" e um "gémeo mau" (ou, por afinidade, na narrativa católica dos irmãos - não gémeos - Caim e Abel); doppelgänger, por seu turno, significa "duplo andante" e a figura remonta ao folclore germânico e é premonição de morte por ser a forma do indivíduo ver a alma fora do seu corpo (FONSECA, 2007, p.188).

De alguma maneira, o que Narciso vê no reflexo é a sua alma fora dele e aquilo de que Narciso não quer prescindir é da imagem que lhe está associada - por isso não toca a água. O toque de Narciso ditaria o fim da imagem; no entanto, a nova imagem de Matt e Mike depende de um toque, menos metafórico, que é o toque da ciência e da técnica realizado pela mão do cirurgião: é ele que constrói e pode destruir a ilusão criada através do corpo. Deste ponto de vista - e se os irmãos trocarem de lugar com Brad Pitt, - Narciso (o actor) não se mira mais nas águas mas no plástico, a matéria que pode ser moldada (quase) infinitamente e se distancia da Natureza. A imagem que se associa a este Narciso é a da peça Narcissus Garden (1966), de Yayoi Kusama, onde o espectador se pode ver reflectido em cento e cinquenta bolas de plástico (RODENBECK, 1996, p.152-53).

\section{Considerações Finais}

A existência e o aparente sucesso de concursos televisivos que têm como motivo a alteração do corpo demonstra a importância que, contemporaneamente, é atribuída à aparência enquanto mostruário das qualidades e nível de sucesso dos indivíduos. 


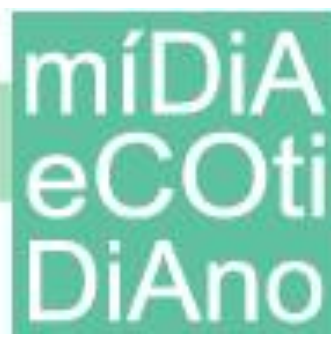

Propostas como a de I Want a Famous Face apresentam, de forma evidente e sem qualquer tipo de filtro, a qualidade da influência que as figuras públicas exercem sobre os indivíduos - aqui, a necessidade de encontrar modelos de conduta transforma-se no desjo de copiar $x$; de, através da aproximação a uma celebridade, conseguir um grau de sucesso semelhante.

Actualmente, e findas as designadas "grandes narrativas" (LYOTARD, 1989, p.40), a necessidade de encontrar directizes reforça o estatuto das ditas celebridades, figuras que preenchem o imaginário dos indivíduos e onde se sintetizam ideais de sucesso e felicidade. Se, noutros períodos, estratégias que passavam pela ateração da aparência eram consideradas enganosas e deviam permanecer ocultas (o desejo de “passar”), hoje, valoriza-se a vontade de mudar no sentido da adequação aos modelos aceites - a cirurgia passa a certificar essa vontade e capacidade de progredir. Nesta demanda, o corpo surge enquanto motivo nostálgico - é um corpo a quem a "aura" pertence enquanto, simultânea e paradoxalmente, é o corpo que pode ser alterado e reproduzido.

Em I Want a Famous Face é adoptada a aparência de um indivíduo particular e o corpo é transformado de forma permanente através da cirurgia estética. A aceitação de um modelo estrito faz dos indivíduos cópias, enquanto o modelo é reforçado e quebrase a relação tradicional entre ver e conhecer pois, ao assumirem aparências iguais às do modelo, perde-se a possibilidade de, através da aparência, expressar uma alma ou uma personalidade única e coloca-se em causa a relação entre a originalidade da aparência e a singularidade humana. Paradoxalmente, a consideração da hipóteses de todos ou de vários indivíduos terem aparências semelhantes - situação que, na sua génese, depende da atenção e valorização do corpo - tem como consequência a valorização da alma pois, se todos os corpos são iguais, a única forma de diferenciação é a expressão da interioridade subjectiva. 
Referências

ADORNO, Theodor W. Sobre a Indústria da Cultura. Coimbra: Angelus Novus, 2003.

ATLAN, Henri [et.al.]. Clonagem Humana [1999]. Coimbra: Quarteto, 2001.

BACHELARD, Gaston. A Água e os Sonhos. Ensaio sobre a Linguagem e Matéria [1942]. São Paulo: Martins Fontes, 1989.

BAUMAN, Zygmunt. Modernidade Líquida. Rio de Janeiro : Jorge Zahar Editora, 1997.

BENJAMIN, Walter. A Obra de Arte na Era da sua Reprodutibilidade Técnica. In Sobre Arte, Técnica, Linguagem e Política [1936]. Lisboa: Relógio d’Água, 1992.

BOLTER, Jay David ; GROMALA, Diane. Windows and Mirrors. Interaction Design, Digital Art, and the Myth of Transparency. Cambridge: The Mit Press, 2003.

CAVELL, Stanley. The World Viewed. Reflections on the Ontology of Film. Cambridge: Harvard University Press, 1979.

COLERIDGE, Samuel Taylor. Biographia Literaria. In ENGELL, James ; BLAIN, W. Jackson (ed.). The Collected Works of Samuel Taylor Coleridge. Princeton: Princeton University Press, 1983. Vol.7.

CORDEIRO, Marta. Ser Belo. Uma Questão Pessoal. Mídia e Coitidiano. Revista Electrônica do Programa de Pós-Graduação em Mídia e Coitidiano. Vol. 4, N.2. Rio de Janeiro: Universidade Federal Fulminense, Junho de 2014.

CORREIA, Carlos João. Schiller e o Problema da Identidade Pessoal. In SANTOS, Leonel Ribeiro dos (coord.). Educação Estética e Utopia Política. Lisboa: Colibri, 1996.

COSTA, J. Almeida ; MELO, A. Sampaio. Dicionário da Língua Portuguesa. Porto: Porto Editora, 1999.

COTTINGHAM, John. Dicionário Descartes [1993]. Rio de Janeiro: Jorge Zahar Ed., 1995.

DEBORD, Guy. A Sociedade do Espectáculo [1967]. Lisboa: Mobilis in Mobili, 2005.

DENNETT, Daniel C. Tipos de Mentes [1996]. Mafra: Rocco, 2001.

DESCARTES, René. Philosophical Essays and Correspondence. Cambridge: Hackett Publishing Company, 2000.

- Os Principios da Filosofia [1644]. Lisboa: Guimarães Editores, 1998.

DIDI-HUBERMAN, Georges. O Que Nós Vemos, O Que Nos Olha [1992]. Porto: Dafne Editora, 2011.

DUBOIS, Phillipe. O Acto Fotográfico [1982]. Lisboa: Vega, 1991. 
ECO, Humberto (dir.). História do Feio. Algés: Difel, 2007.

ELKINS, James. From Original to Copy and Back Again. In The British Journal of Aesthetics. Vol. 33, N. 2. Oxford: The British Society of Aesthetics by Oxford University Press, 1993.

FINCHER, David. The Curious Case of Benjamin Button [registo de vídeo]. U.S.A.: Warner Bros./ Paramout Pictures, 2008.

FONSECA, Tony. The Doppelgänger. In JOSHI, S.T. (ed.). Icons of Horror and the Supernatural: an Encyclopedia of Our Worst Nightmares. London: Greenwood Press, 2007. Vol. I, II.

GAUTHIER, Alain. O Virtual é Azul. In Real vs. Virtual. Revista de Comunicação e Linguagens. N. 25. Lisboa: Centro de Estudos de Comunicação e Linguagens/ Edições Cosmos, 1999.

GILMAN, Sander L. Making the Body Beautiful. A Cultural History of Aesthetic Surgery. Princeton \& Oxford: Princeton University Press, 1999.

HAWTHORNE, Nathaniel. The BirthMark. In Mosses from an Old Manse [1846]. U.K.: Assistedreadingbooks, 2006. Vol. I.

JAY, Martin. In The Empire of the Gaze. In HOY, David Couzens (ed.). Foucault: A Critical Reader. New York: Blackwell, 1986.

LYOTARD, Jean-François. A Condição Pós-Moderna. Lisboa: Gradiva, 1989.

MARRINAN, Michael ; GUMBRECHT, Hans Ulrich (ed.). Mapping Benjamin: The Work of Art in the Digital Age. Stanford: Stanford University Press, 2003.

McNEIL, Legs ; McCAIN, Gillian. Please Kill Me. The Uncensored Oral History of Punk. New York: Grove Press, 2006.

MEDEROS, Margarida. Fotografia e Verdade. Uma História de Fantasmas. Lisboa: Assírio \& Alvim, 2010.

MIRANDA, José A. Bragança de. Corpo e Imagem. Lisboa: Nova Vega, 2008.

MITCHELL, W.J.T. What do Pictures Want? The lives and Loves of Images. U.S.A.: The University of Chicago Press, 2005.

ORTEGA, Francisco. O Corpo Incerto. Corporeidade, Tecnologias Médicas e Cultura Contemporânea. Rio de Janeiro: Garamond, 2008.

OVÍDIO. Narciso e Eco. In Metamorfoses. Livro III. Lisboa: Livros Cotovia, 2007.

ROBINS, Kevin. Consuming Images: From the Symbolic to the Psychotic. In Into the Image. Culture and Politics in the Field of Vision. London: Routledge, 1996. 
RODENBECK, J. F. Yayoi Kusama: Surface, Stitch, Skin. In ZEGHER, M. Catherine. Inside the Visible. An Elliptical Traverse of $20^{\text {th }}$ Century Art In, Of, and From Feminine. Massachusetts: The Mit Press, 1996.

SCHWARTZ, Hillel. The Culture of the Copy. Striking Likenesses, Unreasonable Facsimiles. New York: Zone Books, 1998.

SPIELBERG, Steven. A.I. Artificial Intelligence [registo de vídeo]. U.S.A.: Dream Works/ Warner Bros., 2001.

VIRILIO, Paul. Aesthetics of Disappearance. U.S.A.: Semiotext(e), 1991.

- Cibermundo: A Política do Pior. Lisboa: Teorema, 2000.

WILLIAMS, Bernard. Are Persons Bodies. In SPICKER, Stuart F. (ed.). The Philosophy of the Body. Chicago: Quadrant Books, 1970. 